\title{
Formation of Long-Term Locomotor Memories Is Associated with Functional Connectivity Changes in the Cerebellar-Thalamic-Cortical Network
}

\author{
(-)Firas Mawase, ${ }^{1,5,6}$ Simona Bar-Haim, ${ }^{2,5}$ and DLior Shmuelof $^{3,4,5}$ \\ ${ }^{1}$ Department of Biomedical Engineering, ${ }^{2}$ Department of Physical Therapy, ${ }^{3}$ Department of Brain and Cognitive Sciences, and ${ }^{4}$ Department of Physiology \\ and Cell Biology, and ${ }^{5}$ Zlotowski Center for Neuroscience, Ben-Gurion University of the Negev, Beer-Sheva 84105, Israel, and ${ }^{6}$ Department of Physical \\ Medicine and Rehabilitation, Johns Hopkins School of Medicine, Baltimore, Maryland 21205
}

\begin{abstract}
Although motor adaptation is typically rapid, accumulating evidence shows that it is also associated with long-lasting behavioral and neuronal changes. Two processes were suggested to explain the formation of long-term motor memories: recall, reflecting a retrieval of previous motor actions, and faster relearning, reflecting an increased sensitivity to errors. Although these manifestations of motor memories were initially demonstrated in the context of adaptation experiments in reaching, indications of long-term motor memories were also demonstrated recently in other kinds of adaptation such as in locomotor adaptation. Little is known about the neural processes that underlie these distinct aspects of memory. We hypothesize that recall and faster relearning reflect different learning processes that operate at the same time and depend on different neuronal networks. Seventeen subjects performed a multisession locomotor adaptation experiment in the laboratory, together with resting-state and localizer fMRI scans, after the baseline and the locomotor adaptation sessions. We report a modulation of the cerebellar-thalamic-cortical and cerebellar-basal ganglia networks after locomotor adaptation. Interestingly, whereas thalamic-cortical baseline connectivity was correlated with recall, cerebellar-thalamic baseline connectivity was correlated with faster relearning. Our results suggest that separate neuronal networks underlie error sensitivity and retrieval components. Individual differences in baseline resting-state connectivity can predict idiosyncratic combination of these components.
\end{abstract}

Key words: cerebellum-thalamic-M1 network; functional connectivity; locomotor adaptation; long-term memory; resting-state fMRI

Significance Statement

The ability to shape our motor behavior rapidly in everyday activity, such as when walking on sand, suggests the existence of long-term motor memories. It was suggested recently that this ability is achieved by the retrieval of previous motor actions and by enhanced relearning capacity. Little is known about the neural mechanisms that underlie these memory processes. We studied the modularity in long-term motor memories in the context of locomotor adaptation using resting-state fMRI. We show that retrieval and relearning effects are associated with separate locomotor control networks and that intersubject variability in learning and in the generation of motor memories could be predicted from baseline resting-state connectivity in locomotor-related networks.

\section{Introduction}

Motor adaptation refers to the process by which subjects modify their behavior by changing their internal model based on sensory prediction errors that are perceived from the environment (Shadmehr and Mussa-Ivaldi, 1994; Wolpert and Kawato, 1998). In dozens of trials, subjects modified their motor commands to

Received Aug. 30, 2016; revised 0ct. 21, 2016; accepted 0ct. 29, 2016.

Author contributions: F.M., S.B.-H., and L.S. designed research; F.M. performed research; F.M. and L.S. analyzed data; F.M., S.B.-H., and L.S. wrote the paper.

This study was supported by the German-Israeli Foundation for Scientific Research, the National Institute for Psychobiology-Israel, and the Helmsley Charitable Trust through the Agricultural, Biological and Cognitive Robotics Initiative of Ben-Gurion University of the Negev. We thank Avi Mendelson and Nicholas Wymbs for their discussion and useful comments and llan Shelef and Moti Salti for their help in data acquisition. account for the perturbation and to bring their performance errors back to baseline levels (Thoroughman and Shadmehr, 1999). These adaptation processes were accompanied by after-effects, indicating that the adaptation was driven by adaptation of internal models, and by savings-faster adaptation for repeated exposures to the same perturbation, which is assumed to be the outcome of a consolidation process (Ebbinghaus, 1913; Shad-

The authors declare no competing financial interests.

Correspondence should be addressed to Firas Mawase, Department of Physical Medicine and Rehabilitation, Johns Hopkins School of Medicine, 707 N. Broadway Ave, Room G12, Baltimore, MD 21205. E-mail: fmewasi1@jhmi.edu.

DOI:10.1523/JNEUROSCI.2733-16.2016

Copyright $\odot 2017$ the authors $\quad 0270-6474 / 17 / 370349-13 \$ 15.00 / 0$ 
mehr and Brashers-Krug, 1997; Della-Maggiore and McIntosh, 2005; Krakauer et al., 2005; Debas et al., 2010; Landi et al., 2011). Currently, savings in motor adaptation is explained by two different processes: recall, reflecting a retrieval of previous successful actions (Huberdeau et al., 2015), and increased error sensitivity, which is an enhancement of the learning when the same perturbation is introduced again (e.g., faster relearning; Herzfeld et al., 2014).

Adaptation is not restricted to reaching movements and can be seen in other behaviors such as walking. In locomotor adaptation, subjects walk on a split-belt treadmill that imposes different walking speeds to each leg. When exposed to such a perturbation, subjects change the velocity of the right and left strides to maintain the stability and the efficiency of their walking pattern (Reisman et al., 2005; Choi et al., 2009). As in the case of reaching, locomotor adaptation shows both recall and relearning effects, suggesting the existence of separate long-term locomotor adaptation memory components (Malone et al., 2011; Mawase et al., 2014, 2016; Roemmich and Bastian, 2015).

Compelling evidence suggests that the cerebellum and the motor cortex are involved in the adaptation and acquisition of new locomotor behaviors (Morton and Bastian, 2006; Ilg et al., 2008). Damage to the cerebellum compromises adaptation performance of walking tasks (Horak and Diener, 1994; Morton and Bastian, 2006). Excitability changes in the cerebellum are correlated with the magnitude of behavioral adaptation during walking in healthy individuals (Jayaram et al., 2011). Studies show that the descending component of the midline vermis and fastigial nuclei output of the cerebellum are involved in the control of whole-body posture and locomotion (Chambers and Sprague, 1955; Ghez and Thach, 2000) and receive inputs from the motor cortex (Coffman et al., 2011) through pathways that involve the thalamus (Middleton and Strick, 1994; 1997). Although the involvement of the cerebellarcortical pathway in locomotor adaptation learning is well established, the neural substrates of the formation of long-term motor memories of adaptation are still largely unknown.

Here, we investigate the neuroanatomical and behavioral correlates of adaptation, recall, and relearning. Adaptation describes the short-term error reduction when subjects are exposed to the external perturbation for the first time (i.e., short-term process; day 2). Recall refers to the retrieval of a previous motor pattern from the memory and is approximated by the initial bias observed when subjects returned to the experimental setup $24 \mathrm{~h}$ after the first learning session (with no washout between the sessions; day 3). Relearning effect describes the enhancement of the adaptation process when subjects are exposed to the same perturbation again (after a washout session; day 3). Both recall and relearning reflect the formation of a long-term memory of the motor adaptation learning. We took advantage of recent studies showing that fMRI signals during rest are affected by previous neural activity (Fox and Raichle, 2007; Tambini et al., 2010; Makin et al., 2013; Stagg et al., 2014; Hahamy et al., 2015), by offline consolidation processes (Albert et al., 2009a; Censor et al., 2014; McGregor and Gribble, 2015) and reflect individual traits that are correlated with performance in a variety of cognitive and motor tasks (Taubert et al., 2011; Vahdat et al., 2011; Cole et al., 2014; Bassett et al., 2015; Sampaio-Baptista et al., 2015).

\section{Materials and Methods}

Subjects. Seventeen healthy adult subjects (eight females, mean age $27.94 \pm 12.69$ SD years, mean weight $58.71 \pm 12.69$ kilograms) were recruited to and gave written consent to participate in the study, which was approved by the Helsinki committee of the local Institutional Review Board of Soroka Medical Center, Beer-Sheva, Israel. Subjects were naive to the purpose of the study and none of them had a history of neurological disease and/or psychological disorders.

Experimental procedure. The study was composed of three split-belt walking sessions performed in the laboratory and two MRI sessions. On the first day, subjects first underwent a familiarization baseline walking session on a custom treadmill. After this baseline session, subjects were transported to the MRI room and underwent the first MRI scan. Subjects then went home and were instructed not to walk on a treadmill later that day. On the subsequent day, subjects came to the laboratory and performed a split-belt treadmill adaptation session that lasted $20 \mathrm{~min}$. They were then transported to the MRI room and underwent an identical MRI session to the one performed the previous day. Approximately $24 \mathrm{~h}$ later, subjects came again to the laboratory and were retested on the split-belt treadmill for retention estimation (see Fig. $1 B, C$ ).

Behavioral task. Subjects participated in three behavioral sessions on three consecutive days (see Fig. $1 B, C$ ). On the first day, subjects were familiarized with the experimental setup and underwent 20 min of baseline walking on a custom split-belt treadmill (ForceLink). During baseline, they walked with the two belts linked at a slow speed $(0.7 \mathrm{~m} / \mathrm{s})$. Subjects were then transported to the imaging center and underwent the first MRI scan (i.e., scan ${ }_{1}$ ) which lasted $\sim 1$ h. On the second day, subjects underwent the second behavioral session consisting of a perturbation in the speed of the belts. During the split-belt adaptation condition, subjects walked for $20 \mathrm{~min}$ in a split-belt regimen in which each leg was exposed simultaneously to a different belt speed with the ratio of 1:2. The dominant leg walked at the slower speed $(0.7 \mathrm{~m} / \mathrm{s})$ and the nondominant leg walked at the faster speed $(1.4 \mathrm{~m} / \mathrm{s})$. Immediately after this session, subjects were transported to the imaging center and underwent the second MRI scan (i.e., $\operatorname{scan}_{2}$ ). The transportation from the laboratory to the scanner was done to prevent washing out the adapted pattern, which was shown previously to occur if subjects walk overground immediately after adaptation (Torres-Oviedo and Bastian, 2012). On the third day, subjects returned to the laboratory and performed three consecutive blocks of walking. In the first block, subjects were exposed to the same split-belt condition for an extra $10 \mathrm{~min}$ (the dominant leg was set to walk at $0.7 \mathrm{~m} / \mathrm{s}$, whereas the nondominant leg was set to walk at $1.4 \mathrm{~m} / \mathrm{s}$ ). In the second block, belts were tied together and the adapted pattern was washed out. This session lasted $10 \mathrm{~min}$ (with the two belts tied together at a slow speed of $0.7 \mathrm{~m} / \mathrm{s}$ ). The subject then readapted to the split-belt perturbation for another $20 \mathrm{~min}$. Each minute of walking on the splitbelt treadmill included $\sim 40$ strides. Each stride started at left initial contact on the force plates and terminated at the subsequent initial contact of the same leg. Subjects were not notified concerning the perturbation schedule.

Behavioral estimate of adaptation, recall, and relearning effect. Because we were studying motor adaptation, which is thought to be an errordriven process, we adopted the step asymmetry as our measure of the motor error in each gait cycle as follows: step asymmetry $=($ left COP length - right COP length)/(left COP length + right COP length), where COP is the center of pressure, the length of which was calculated as the distance between the point where the foot touched the belt and the toe of the opposite leg lifted off the belt (data were sampled at $500 \mathrm{~Hz}$ ). When the step asymmetry value is zero, it describes symmetric walking and, when it is other than zero, it means that the gait is not symmetric (Reisman et al., 2005). The underlying assumption of the locomotor adaptation task is that the deviation of the step length from zero is proportional to the error signal that subjects perceive and try to reduce through the adaptation process (Reisman et al., 2009; Torres-Oviedo et al., 2011). "Adaptation" in day 2 was quantified as the difference between initial errors at the early phase of the adaptation session and asymptotic performance (i.e., error at the late phase of the adaptation) of the same session. Initial error was quantified as the mean of the first two strides in the adaptation phase while asymptotic performance was related to the mean of the last 50 strides. "Relearning effect" (increased error sensitivity), or enhancement in the learning rate during readaptation, was estimated as the signed difference between mid-errors during readaptation of day 3 and mid-errors during adaptation of day 2. Mid-adaptation error was quantified as the mean of the strides 3-50. These mid-errors represent a common model-free approximation for learning rates in locomotor ad- 
aptation. The advantage of this estimate of learning rate is that it does not rely on an assumption regarding a specific pattern of adaptation, as would, for example, a single or double exponential fit. "Recall" of the adapted pattern $24 \mathrm{~h}$ later was estimated as the initial bias observed $24 \mathrm{~h}$ after the initial learning session. The initial bias was quantified as the difference between initial error of day 3 and the initial error of day 2 . Relearning effect and initial bias are illustrated in Figure $2 A$. Our estimates of adaptation, relearning effect, and recall are consistent with convention and have been used commonly in human locomotion literature (Malone et al., 2011; Mawase et al., 2014). Repeated-measures one-way ANOVA was used to test for adaptation, recall, and relearning. When ANOVA revealed significant effect, post hoc analysis was conducted using the Holm-Sidak test to correct for multiple comparisons.

MRI sessions. Two identical sessions were performed on days 1 and 2 . Each session began with a T1-weighted high-resolution anatomical scan followed by a $12 \mathrm{~min}$ resting-state fMRI scan, which was followed by a 9.5 min localizer scan and diffusion tensor imaging (DTI) scan (not reported here). During the T1-weighted high-resolution anatomical scan, subjects were allowed to close their eyes. In the resting-state scan, subjects were instructed to rest quietly with their eyes open and to focus on a cross sign $(+)$ viewed through mirror glasses that reflect the screen view. In the localizer scan, subjects were instructed to move their limbs as cued by a string shown in the screen. Specifically, five conditions were performed in this scan: (1) right leg movements (movements of the ankle), (2) left leg movement, (3) right and left legs' movements, (4) right wrist movements, and (5) left wrist movements. During movement blocks, subjects were instructed to keep their head stable and to move only the corresponding limb at a frequency of $1 \mathrm{~Hz}$ (i.e., 1 cycle per second) as demonstrated by the experimenter before the scans. Specifically, hand movement blocks involved slow cyclic wrist movements of the corresponding hand that were $\sim 10 \mathrm{~cm}$ in amplitude in an outward direction away from the body in the sagittal plane and leg movement involved slow cyclic ankle stepping of the corresponding leg that were $\sim 10 \mathrm{~cm}$ in amplitude. Movement blocks were interleaved by rest periods of $10 \mathrm{~s}$ that were cued by a "+" sign on the screen. In total, the localizer scan includes five repetitions of each of the five movement conditions. Both scans (i.e., scan ${ }_{1}$ and $\operatorname{scan}_{2}$ ) were identical and lasted $\sim 1 \mathrm{~h}$. Scan ${ }_{1}$ was performed on the first day, immediately after baseline evaluation of walking, and $\mathrm{Scan}_{2}$ was performed on the subsequent day immediately after the adaptation session.

MRI acquisition. MRI scans were performed in the imaging center at the Soroka Medical Center using a 3 tesla Philips Achieva MRI scanner (Koninklijke; Philips Electronics). Functional data were collected by using a gradient echo EPI, with voxel size of $3 \times 3 \times 3 \mathrm{~mm}$, TR $=2000 \mathrm{~ms}$, $\mathrm{TE}=35 \mathrm{~ms}, 35$ axial slices per TR with a $0.6 \mathrm{~mm}$ gap, $96 \times 96$ acquisition matrix, flip angle of $77^{\circ}$, and FOV $192 \mathrm{~mm}$ to cover the entire cerebellum and cerebral cortex. We used a gap of $0.6 \mathrm{~mm}$ ( $20 \%$ of slice thickness) to reduce the crosstalk between slices. The first two volumes were discarded to allow magnetization to reach equilibrium. A high-resolution anatomical image was acquired using a single T1-weighted anatomical scan (with voxel size of $1 \times 1 \times 1 \mathrm{~mm}, \mathrm{TR}=8.165 \mathrm{~ms}, \mathrm{TE}=3.74 \mathrm{~ms}, 256 \times 256$ acquisition matrix). The FOV covered the entire cerebrum and the cerebellum.

Preprocessing of functional data. fMRI data preprocessing was performed in Brain Voyager QX 2.80 (Brain Innovation) and includes the following steps: (1) removal of the first two functional images of each run series to allow stabilization of the magnet; (2) slice-time correction; (3) head motion correction using trilinear interpolation; (4) temporal highpass filtering ( $0.0045 \mathrm{~Hz}$ cutoff frequency); and (5) spatial smoothing using Gaussian kernel (FWHM of $6 \mathrm{~mm}$ ). Functional images were then aligned to the T1-weighted structural image and incorporated into the 3D datasets through trilinear interpolation. Data were then transformed into Talairach space and $z$-normalized.

Regions of interest (ROIs). Three ROIs along the cerebellar-thalamiccortical pathway of the left, nondominant, leg were examined. Our regions include ipsilateral cerebellar cortex, contralateral primary motor cortex (M1), and contralateral thalamus. For connectivity analysis, the coordinates of the cerebellar and cerebral regions were identified using a localizer scan that was performed after the resting-state scan. The coordinates in each of the ROIs were selected on the basis of activation peaks obtained from the block design analysis. The entire contralateral tha- lamic coordinates were defined for each subject using automatic anatomical segmentation performed by FreeSurfer software (Reuter et al., 2012). We then averaged the BOLD signal across all voxels of the ROI for the functional connectivity analysis. We chose this approach based on the observation that the resting-state activation in the thalamus is highly correlated across space. For each subject, we obtained the mean BOLD signal of each ROI by defining a mask around the seed in the standard space. The cortical ROI was on average a sphere of radius $7 \pm 0.15 \mathrm{~mm}$ (mean \pm SEM) with its center located at the activation peak. The cerebellar ROI was on average a sphere of radius $5.5 \pm 0.15 \mathrm{~mm}$ and the thalamic ROI was on average a sphere of radius $12 \pm 0.15 \mathrm{~mm}$.

Distortion and change in activation concerns during the localizer scans. Performance of leg movements during the localizer may lead to significant head motions and to inhomogeneities in the magnetic field, which would result in erroneous selection of ROIs. To ensure that this distortion was not present in our data, we performed three control analyses: (1) we verified that head motion did not exceed a threshold of $1 \mathrm{~mm}$ and did not differ between scans; (2) to address possible inhomogeneities in the magnetic field, the alignment of the functional data was based on its first volume, which is the optimal volume for the intensity-driven fine tuning alignment step and is not affected by movement because subjects are at rest at this stage; and (3) to address specifically the concern that inhomogeneities in the magnetic field may lead to erroneous activation patterns, we ran a general linear (GLM) model with predictors associated with the movement conditions (without a convolution with an HRF) and searched for activation outside of the brain. We found no significant activation of voxels outside the brain. Together, the above results support the conclusion that our movement epochs did not elicit marked inhomogeneities in the magnetic field.

Another concern is that the locomotor adaptation session will lead to changes in the activation patterns that are measured during the localizer scan and that these changes will subsequently bias the selection of the ROIs. To address this concern, we ran a GLM model and calculated the $\beta$ values for each seed in each localizer scan (i.e., $\operatorname{scan}_{1}$ and $\operatorname{scan}_{2}$ ). We found no evidence for changes $(p>0.18)$ in activation related to training and no correlation $(r<0.32, p>0.19)$ between learning metrics and activation strength during the localizer sessions. We therefore conclude that subjects demonstrated comparable functional activations in the localizer sessions across days.

Functional connectivity (FC). Several processing steps were used to isolate the meaningful patterns of activation that are specific to the areas of interest. All resting-state BOLD signals were first preprocessed as described in the previous session. In addition, further steps were used to clean the signals from global activation patterns: (1) temporal band-pass filtering using an eighth-order Butterworth filter with cutoff frequencies of $0.009<f<0.08 \mathrm{~Hz}$ to remove unwanted physiological signals such as heart rate and respiratory signals (Fox and Raichle, 2007) and (2) projection out the nuisance signals of white matter, CSF, and six motion parameters $(x, y$, and $z$ translations and rotations obtained from the motion correction step in preprocessing). This step was conducted by running a multiple GLM regression analysis with all nuisance signals. The residual of this analysis was free from these components and was used as the input for the subsequent correlation analyses.

For each subject, we then calculated the Pearson correlation coefficients (i.e., $r$ ) between the BOLD time courses of our predefined ROIs. To minimize multiple comparisons concerns, we limited our correlation comparisons to be within the cerebellar-thalamic-cortical pathway of the left, nondominant, fast leg becausee it was shown that applying transcranial direct current stimulation (tDCS) over the cerebellum ipsilateral to the fast leg and not to the slow leg enhanced locomotor adaptation (Jayaram et al., 2012). For statistical analysis across subjects, we first converted the correlation coefficients (i.e., $r$ ) to normal distribution using $z$-Fisher's transformation. These values were then normalized using $z$-scores (i.e., normally distributed, zero mean, and unit variance). We then calculated the change of functional connectivity (i.e., $\Delta \mathrm{FC}$ ) after adaptation as the change of FC from day 1 (before adaptation) to day 2 (after adaptation). The resulting values were compared with the null hypothesis of no change in functional connectivity across days by using a paired-sample $t$ test with a significant level of 0.05 . To correct for multi- 
ple comparisons, we used the Holm-Sidak $t$ test and restricted our comparisons to be within the anatomical pathway (i.e., 3 ROIs for each comparison; e.g., ipsilateral cerebellum-contralateral thalamus-contralateral M1).

We used a Pearson correlation test (i.e., $r$ ) to examine the relationship between the behavior measures and the FC. To verify that the correlation results that we found among baseline functional connectivity, relearning effect, and recall were not the result of the small sample that might be affected by outliers, we used a bootstrap test to estimate the effect of possible outliers on our results. Specifically, the bootstrap was performed using 10,000 unique combinations drawn with replacement from the subject pool. The $95 \%$ confidence intervals were calculated as the 2.5 and 97.5 percentile values from the distribution for each coefficient obtained across the 10,000 fits. In addition, to verify that the correlation results were not affected by outliers, we also ran a robust regression analysis using the Matlab function robustfit $(x, y)$ with a tuning constant of 2.795. These analyses allow addressing the concern that the correlation that was found was driven by an outlier.

Seed voxel-based functional connectivity analysis. The second objective of the current study was to explore the connectivity maps that were calculated. For each ROI, the mean BOLD time course was used as a predictor in a multisubject GLM to evaluate the functional connectivity of that seed with every voxel in the brain. In addition, to account for potential contributions of physiological noise, the time course of nuisance signals of white matter, CSF, and six motion parameters were also included as predictors in the same GLM. This analysis ends with an activation map of all voxels in the brain that correlated with the seed of interest. We minimized detection of false positives (type II error) by using a cluster-corrected familywise error rate correction at $p<0.05$. The correction procedure used Monte Carlo simulations to calculate the probability of having a cluster of a certain size being due to chance (noise) alone; therefore, it computes the probability of a random field of noise producing a cluster of a given size after the noise is thresholded at a given level (Wymbs et al., 2012). Our $z$-statistic images then were projected onto an inflated template brain. This analysis was conducted separately for $\operatorname{scan}_{1}$ (before adaptation) and $\operatorname{scan}_{2}$ (after adaptation). For further group analysis, we used random-effects analysis (RFX in Brain Voyager) to compute across-day comparison (day $2>$ day 1 ). To investigate the strength of the connectivity changes at the single-subject level, we calculated the $\beta$ values for each voxel underlying the connectivity maps in individual participants. These values represent the strength of connectivity between the seed area and the individual voxels. Analyses of the distribution of the $\beta$ values across subjects were done to estimate connectivity patterns.

Independent component analysis (ICA). Data were further analyzed using the ICA method in Brain Voyager. ICA estimates maximally statistical independent, non-Gaussian components from resting-state fMRI data. First, ICA was computed on the individual resting-state scans. We chose a model order of 30 independent components that capture mostly the full set of canonical networks as described previously (Beckmann et al., 2005). We then classified the components based on previous knowledge of the resting-state network patterns and focused on three networks of interest (sensorimotor, cerebellar, and frontoparietal; Albert et al., 2009b). This method allows identifying major networks on a subject-bysubject basis during the resting-state scans and measuring changes in the strength of these components after motor adaptation. For representation purposes, activation maps showing each of the networks of interest were projected on the inflated surface of the cortex. We compared the averaged component related activation across the networks before and after learning. We then examined the strength of these components on the voxel level using contrasts by using "self-organizing group" in Brain Voyager. We minimized detection of false positives (type I error) by using cluster-corrected familywise error rate correction at $p<0.05$.

\section{Results}

Our protocol consisted of locomotor adaptation sessions in the laboratory and resting-state fMRI scans. Specifically, participants first performed a baseline locomotor task with no perturbation in the laboratory and then a baseline resting-state fMRI scan. On the
A

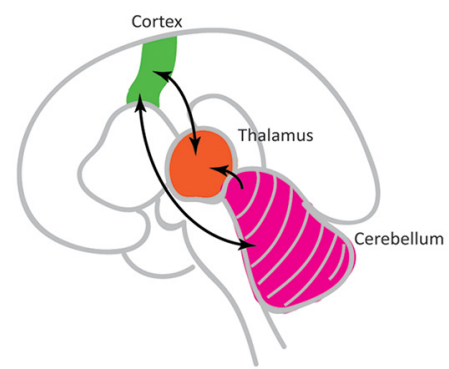

B

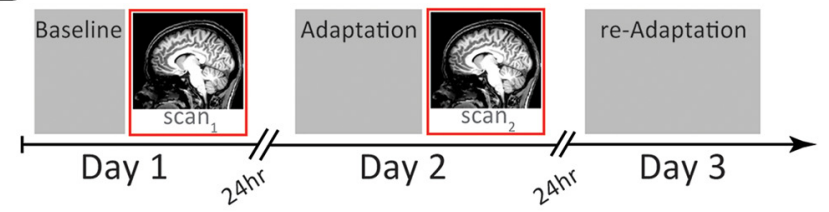

C

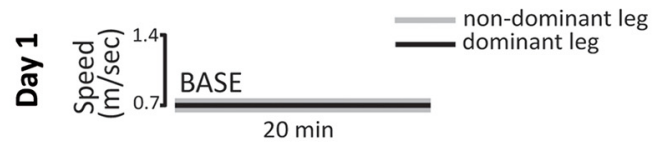

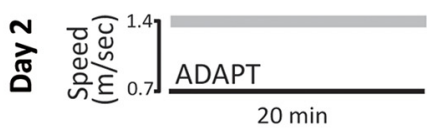

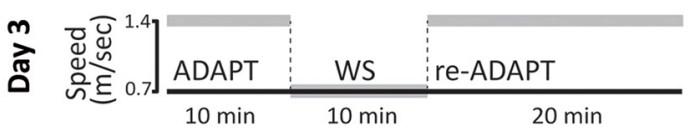

Figure 1. Experimental design. $\boldsymbol{A}$, Schematic diagram of the main neural pathways of interest underlying locomotor adaptation: cerebellum, thalamus, and the motor cortex. $\boldsymbol{B}$, Subjects participated in 3 split-belt walking sessions performed in the laboratory and 2 MRI sessions over 3 subsequent days. 0 n the first day, subjects first underwent a familiarization baseline walking session on a customized treadmill. After this baseline session, subjects were transported to the MRI room and underwent the first MRI scan. On the subsequent day, subjects came to the laboratory and performed a split-belt treadmill adaptation session. They were then transported to the MRI room and underwent an identical MRI session to the one performed the previous day. Approximately $24 \mathrm{~h}$ later, subjects came again to the laboratory and were retested on the split-belt treadmill for retention and savings estimation. C, On the first day, subjects performed a baseline walking session for $20 \mathrm{~min}$ with no perturbation. They were then transported to the scanner and underwent the first MRI scan. On the second day, subjects adapted to the split-belt novel treadmill for $20 \mathrm{~min}$ while the nondominant leg walked on the fast belt $(1.4 \mathrm{~m} / \mathrm{s})$ and the dominant leg walked on the slow belt $(0.7 \mathrm{~m} / \mathrm{s})$. Immediately afterward, subjects were transported to the scanner room and underwent the second MRI scan. Twenty-four hours later, subjects returned to the laboratory and were tested for retention by walking for 10 min under the perturbation of the previous day, followed by 10 min of washout (no perturbation condition: equal speeds of $0.7 \mathrm{~m} / \mathrm{s}$ in the both belts). Finally, subjects readapted for 20 min to the split-belt perturbation.

following day, participants adapted to the split-belt perturbation and performed another resting-state fMRI scan. Twenty-four hours after adaptation, retention of the long-term locomotor memory was assessed in the laboratory. Changes in resting-state connectivity in the cerebellar-thalamic-cortical loop (Fig. 1A) and intersubject correlations between connectivity in this network and relearning effect and recall were examined to characterize the neural basis of locomotor adaptation learning and retention. Examination of the intrinsic resting-state functional connectivity patterns allows overcoming artifacts that are associated with recording brain activation during locomotion and therefore provides a unique opportunity to study the neural processes that are involved in locomotor adaptation and retention. 
A

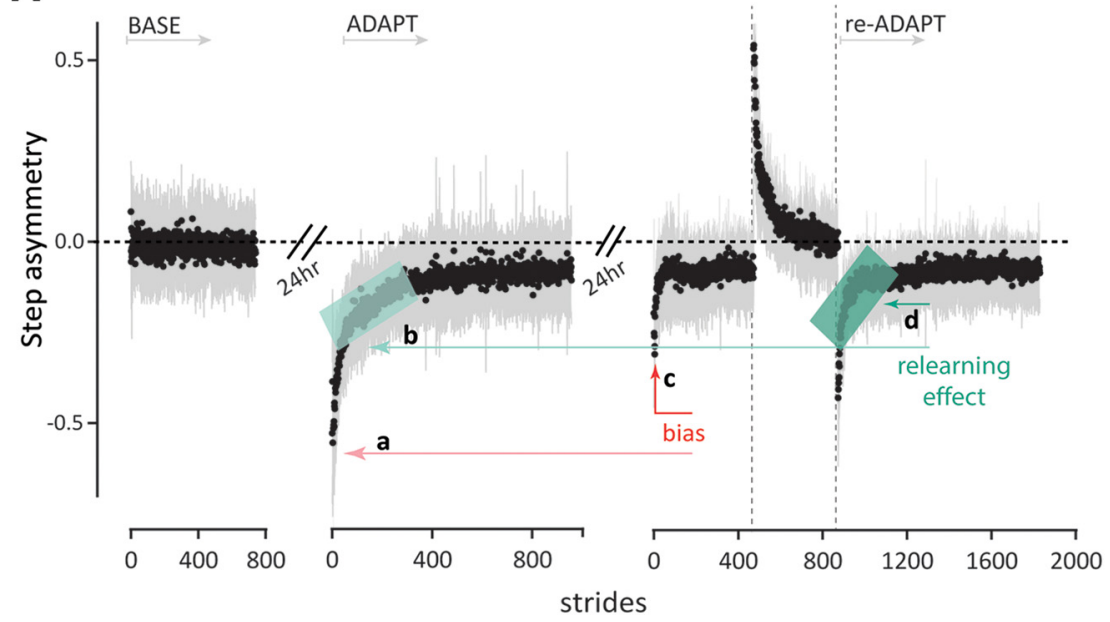

B

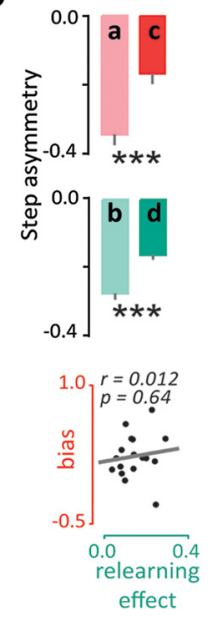

Figure 2. Learning, recall, and relearning performance. $\boldsymbol{A}$, Subjects' mean performance across all sessions as estimated by their step asymmetry measure (i.e., motor error, which is unit-less). Black points represent mean step asymmetry across subjects in each stride. Shaded area represents SD. Recall was estimated for each subject as the change in initial errors (i.e., bias) between day $2(\boldsymbol{A} \boldsymbol{a})$ and day $3(\boldsymbol{A c})$ and the relearning effect was estimated as the signed difference between mid-errors from day 2 ( $\boldsymbol{A} \boldsymbol{b})$ and mid-errors from day 3 ( $\boldsymbol{A} \boldsymbol{d})$. $\boldsymbol{B}$, Subjects showed significant recall (top) and adapted faster to the perturbation on day 3 , indicating relearning effect (middle). Recall and relearning effect measures were not correlated across subjects (bottom). The value of $r$ represents the Pearson correlation coefficient. Points and bars represent the means and error bars represent the SEM. Significance level is ${ }^{* * *} p<0.001$.

Locomotor adaptation: adaptation, recall, and relearning effect

Subjects participated in three behavioral sessions in the laboratory conducted on 3 consecutive days. On the first day, subjects underwent $20 \mathrm{~min}$ of baseline walking, with no perturbation, on a custom split-belt treadmill (ForceLink). On the second day, subjects were exposed to an unexpected perturbation in the speed of the belt, in which the dominant leg walked at a slower speed compared with the nondominant leg (adaptation block, 0.7 vs 1.4 $\mathrm{m} / \mathrm{s}$, respectively). On the third day, subjects returned to the laboratory and performed three consecutive blocks of walkingadaptation, baseline, and readaptation (Fig. $1 A$ ). Subjects were not notified and were typically unaware of the perturbation schedule. The main measure of performance in the locomotor adaptation task is step asymmetry, which is measured in each gait cycle (Reisman et al., 2005). The underlying assumption of the locomotor adaptation task is that the deviation of the step asymmetry from zero (symmetric walking) is proportional to the error signal that subjects perceive and wish to reduce through the adaptation process (see Materials and Methods).

Three measures of locomotor adaptation were examined: adaptation, recall, and relearning (Fig. 2). Adaptation describes the short-term error reduction of step asymmetry when subjects are exposed to the external perturbation for the first time (i.e., shortterm process). The relearning effect describes the enhancement of the adaptation process when subjects are exposed to the same perturbation again (after a washout session). Recall refers to the retrieval of a previous locomotor pattern from the memory and is approximated by the initial bias observed when subjects returned to the treadmill $24 \mathrm{~h}$ after the first learning session (on day 3 , with no washout on the treadmill between the sessions). Both relearning and recall reflect the formation of a long-term memory of the locomotor adaptation learning. Subjects managed to reduce the error induced by the perturbation and showed a significantly smaller error at asymptote compared with their initial error at early adaptation $\left(t_{(16)}=7.47, p<0.0001\right.$; Fig. $\left.2 A\right)$. Subjects also adapted faster to the perturbation on day 3 , indicating a relearning effect $\left(t_{(16)}=8.05, p<0.0001\right.$; Fig. $\left.2 A, B\right)$, and showed a significant recall expressed by the large initial biases that were recorded during the first block of day $3\left(t_{(16)}=4.03, p=0.0029\right.$; Fig. $2 A, B)$. The relearning effect and recall were not correlated $(r=0.012, p=0.64$; Fig. $2 B)$, indicating that these measures may be related to separate processes. Altogether, the data collected in the three sessions in the laboratory consist of information about both short- and long-term learning and retention of adaptation to a split-belt locomotor perturbation. We used here the miderrors as a model-free approximation for learning rates estimate. The advantage of this estimate of learning rate is that it does not assume that the subjects follow a specific learning function. Notably, our model-free estimate (i.e., mid-errors) was significantly correlated with a model-based learning rate as estimated by two-term exponential function (average $R^{2}=0.82 \pm 0.02 \mathrm{SE}$ ) for the quality of the model fits and $(r=-0.78, p<0.00024)$ for the correlation between the estimated parameters and the mid-errors.

\section{Alteration of cerebellar-thalamic-cortical functional connectivity after locomotor adaptation}

The goal of the study was to search for the neural correlates of short- and long-term locomotor adaptation effects by investigating functional connectivity patterns between ROIs. To avoid multiple comparison concerns, we restricted our analysis to ROIs in the cerebellum, the thalamus, and the motor cortex (Fig. 1A). We chose these areas due to the well established functional role of this network in adaptation learning (Fabre et al., 1979; Martin et al., 1996; Chen et al., 2006) and based on the anatomical connections between the dentate nucleus of the cerebellum and the ventrolateral thalamus, which in turn projects to the primary motor cortex, supplementary motor area, and premotor cortex (Sakai et al., 2002; Jeljeli et al., 2003; Stepniewska et al., 2003). We further focused our analysis on the control network of the left, nondominant, leg that walked on the faster belt. This approach is based on the estimation that the adaptation occurs primarily in the control over the faster leg. This estimation is supported by a recent study showing that locomotor adaptation enhancement after applying tDCS over the cerebellum ipsilateral to the fast leg and not to the slow leg (Jayaram et al., 2012).

Motivated by previous evidence showing changes in restingstate connectivity after motor learning (Albert et al., 2009b; Vah- 
A
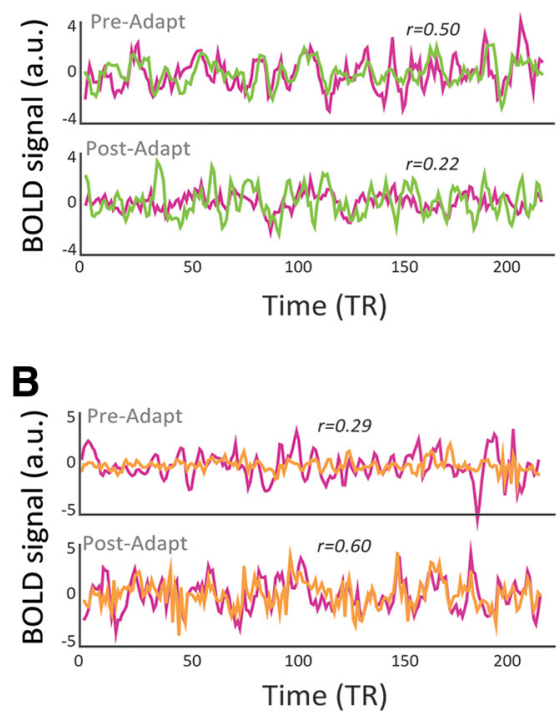

C

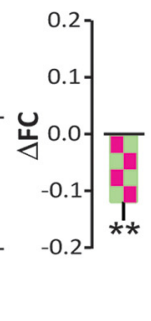

\section{Leg areas}
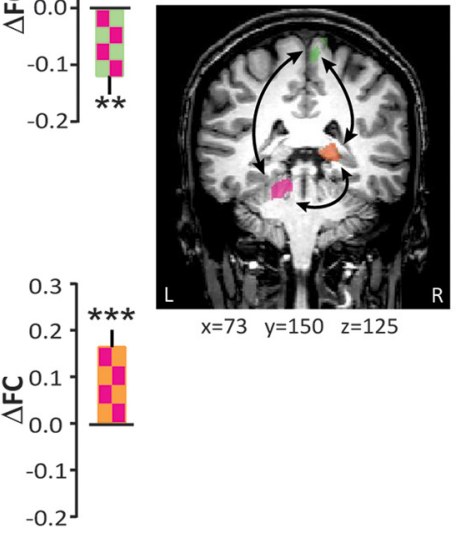

D
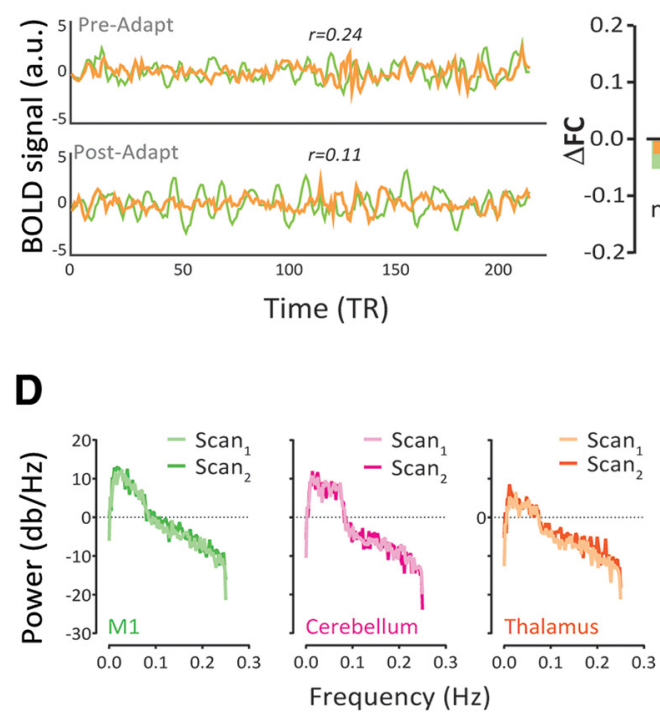

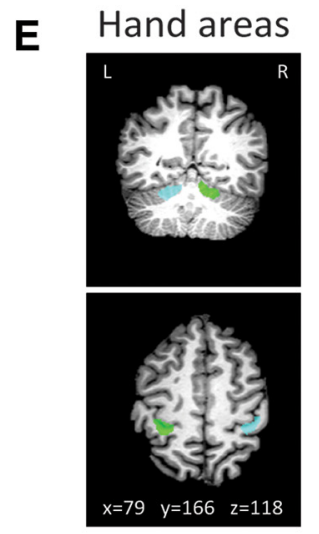

$\mathbf{F}$

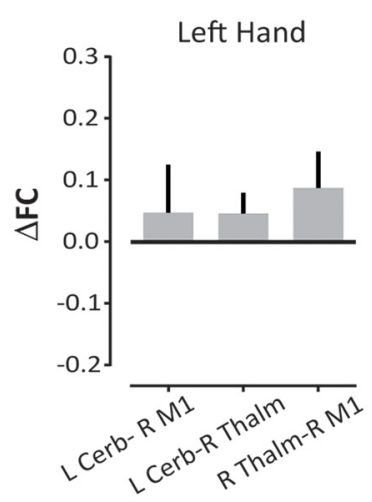

G

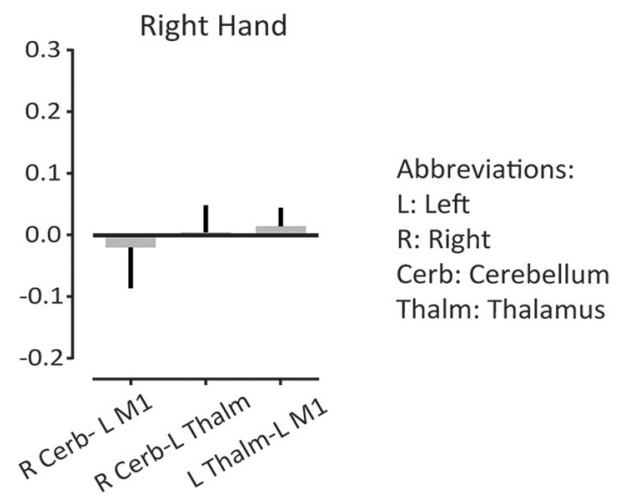

Figure 3. Modulation of cerebellar-thalamic- cortical functional connectivity after locomotor adaptation. $A$, Single subjects' examples of BOLD time courses from the cerebellum (magenta) and M1 (green) during preadaptation scan (top) and postadaptation scans (bottom). Right panel shows the mean $\Delta \mathrm{FC}$ between these ROls. $\boldsymbol{B}$, Single subjects' examples of BOLD time courses from the cerebellum (magenta) and the thalamus (orange) during preadaptation scan (top) and postadaptation scan (bottom). Increased cerebellar-thalamic functional connectivity was detected (right). C, BOLD time courses from the thalamus (orange) and M1 (green) during preadaptation scan (top) and postadaptation scan (bottom). D, Mean power spectrum of the BOLD signal as a function of frequency (in Hertz) for each ROI during preadaptation (light-colored curves) and postadaptation (dark-colored curves) sessions. Left, Power spectrum for M1. Middle, Power spectrum for the cerebellum. Right, Power spectrum for the thalamus. Curves represent mean across subjects. The value of $r$ represents the Pearson correlation coefficient. $\boldsymbol{E}$, Top shows, in a coronal plane, the hand cerebellar regions (cyan for the left hand and green for the right hand). Bottom shows, in a sagittal plane, the hand cerebral regions (cyan and green for left and right hand, respectively). $\boldsymbol{F}$, No significant functional connectivity changes were found in the cerebellar-thalamic- cortical network of the left hand. G, Similar results were found for the right hand. Bars represent the means and error bars represent the SEM. Significance levels are as follows: ${ }^{* *} p<0.0$, ${ }^{* *} p<0.001$.

dat et al., 2011; Della-Maggiore et al., 2015b), we first hypothesized that, because locomotor adaptation involves learning via error correction and control processes, it would affect the resting-state functional connectivity patterns in the cerebellarthalamic-cortical network. We therefore analyzed the changes in the functional connectivity among the cerebellum, thalamus, and the primary motor cortex (i.e., M1) after motor adaptation compared with functional connectivity after baseline walking. ROIs in the cerebellum and in the motor cortex were defined on a subject-by-subject basis using a functional localizer (see Materials and Methods). Because we could not find reliable activation patterns in the thalamus during the localizer scan, this region was defined based on anatomical landmarks only. We detected a significant change in functional connectivity between cerebellumthalamus and cerebellum-M1 networks after motor adaptation relative to baseline connectivity level (Fig. $3 A, B$ shows the time course of BOLD signals from representative subjects). Although the connectivity between the cerebellum and the thalamus increased $\left(\Delta \mathrm{FC}=0.157 \pm 0.03\right.$, mean \pm s.e.m, $t_{(16)}=4.28, p=$ $0.0017)$, the connectivity between $\mathrm{M} 1$ and cerebellum decreased $\left(\Delta \mathrm{FC}=-0.106 \pm 0.03, t_{(16)}=3.38, p=0.0114\right)$. The connectivity between the thalamus and M1 did not change after adaptation $\left(t_{(16)}=0.524, p=0.94\right.$; Fig. $\left.3 C\right)$. To ensure that these effects were not caused by changes in the magnitude of signal fluctuations in each one of the regions, but rather reflect a change in the synchronization between regions, we compared the power spectrum for each BOLD signal between preadaptation and postadaptation (Fig. 3D). After binning the power spectrum of each signal to 8 bins of $0.011 \mathrm{~Hz}$, ANOVA revealed no significant day effect in power $\left(F_{(1,128)}=1.273, p=0.2614\right)$ and no significant day $\times$ frequency interaction $\left(F_{(7,128)}=0.619, p=0.7394\right)$ for the power spectrum of the time course signal for the M1. Cerebellar 
power analysis showed similar statistical results; ANOVA revealed no significant day effect in power $\left(F_{(1,128)}=0.053, p=\right.$ $0.8175)$ and no significant day $\times$ frequency interaction $\left(F_{(7,128)}=\right.$ $0.813, p=0.5778)$. Power analysis of the time course signal for the thalamus showed marginal results; ANOVA revealed a marginal day effect in power $\left(F_{(1,128)}=3.68, p=0.06\right)$, but no significant day $\times$ frequency interaction $\left(F_{(7,128)}=0.579, p=0.7713\right)$.

To ensure that the connectivity effects that we observed after locomotor adaptation were related to formation of locomotor memories and do not reflect general task-independent functional changes, we performed identical functional connectivity analysis to the hand areas. We predicted that cerebellar-thalamic-cortical hand motor networks would not exhibit functional plasticity related to consolidation of locomotor memories. Similar to the main analysis, the coordinates of the cerebellar and cerebral hand regions were identified using a localizer scan that was performed after the resting-state scan and are shown in Figure 3E. The top panel shows, in a coronal plane, the hand cerebellar regions (cyan for the left hand and green for the right hand). The bottom shows, in the sagittal plane, the hand cerebral regions (cyan and green for left and right hand, respectively). Data showed that no significant functional connectivity changes were found in the cerebellarthalamic-cortical network of the left hand (Fig. $3 F$ ) between the left cerebellum and right M1 $\left(t_{(16)}=0.61, p=0.55\right)$, the left cerebellum and right thalamus $\left(t_{(16)}=1.37, p=0.19\right)$, or the right thalamus and right $\mathrm{M} 1\left(_{(16)}=1.48, p=0.16\right)$. Similar results were found for the right hand (Fig. $3 G$ ). No significant connectivity change was observed between the right cerebellum and left $\mathrm{M} 1\left(t_{(16)}=0.30, p=0.77\right)$, between the right cerebellum and left thalamus $\left(t_{(16)}=0.12, p=0.91\right)$ or between the left thalamus and left $\mathrm{M} 1\left(t_{(16)}=0.48, p=0.64\right)$. This result suggests that the changes in connectivity were specifically related to the learning that subjects accomplished between the sessions and were not a simple outcome of the order of the sessions. This conclusion is further supported by the following analyses showing a correlation between connectivity measures and performance in the behavioral sessions.

\section{Baseline functional connectivity in the motor networks predicts long-term memory}

We found a noticeable across-subject variability in initial learning rates. Furthermore, these differences were also noticeable in the performance of subjects on day 3 (Spearman's rank correlation $\rho=0.64, p=0.0069$ ), suggesting that across-subject variability is not a result of measurement or performance noise, but rather represents a consistent difference between the learning ability of the individual subjects. We therefore hypothesized that the baseline resting-state connectivity magnitude between the nodes of the cerebellar-thalamic-cortical network will be indicative of the activation of these networks during adaptation and memory formation processes. For example, individuals who have high network connectivity with the cerebellum may exhibit greater relearning effects than subjects who show weaker network connectivity with the cerebellum. To address this hypothesis, we investigated the relationship between the across-subject connectivity measures at baseline and across-subject adaptation, recall, and relearning effect performances.

We found that baseline functional connectivity between the leg area of the cerebellum and the right thalamus tended to correlate with the learning rate during the adaptation in day $2(r=$ $-0.49, p=0.047$; Fig. $4 A$, left). This relationship was not found when examining the thalamic-cortical baseline connectivity ( $r=0.06, p=0.82$; Fig. $4 A$, right $)$. Interestingly, we found that
A
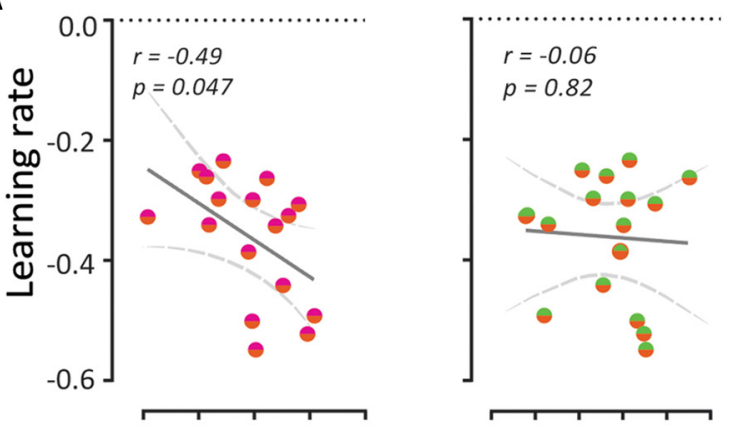

B
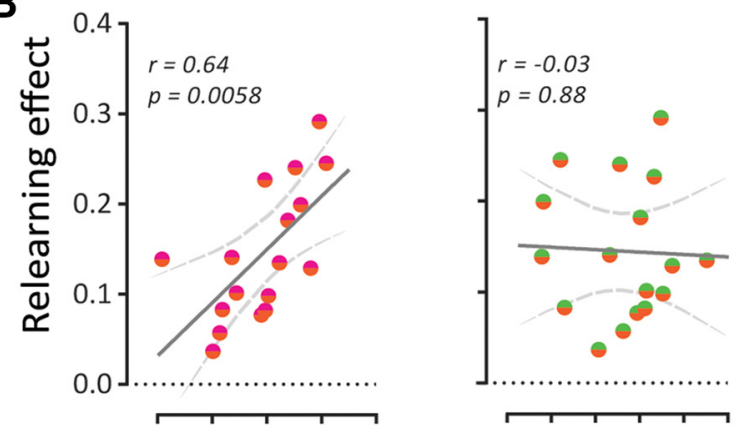

C
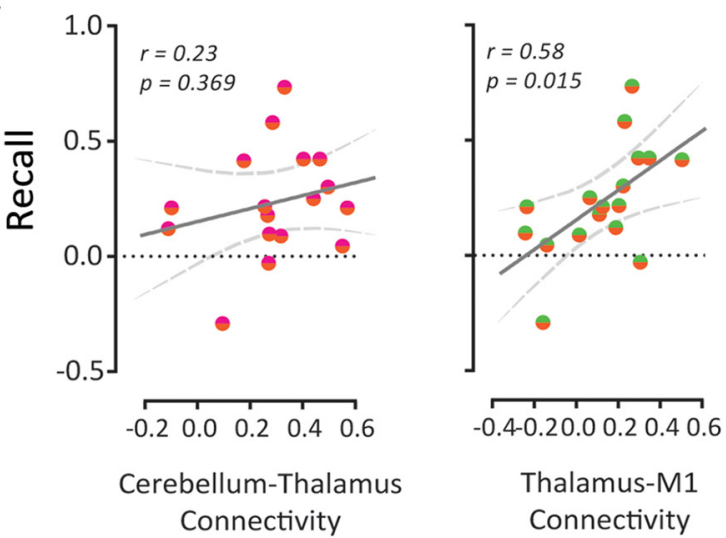

Thalamus-M1

Connectivity

Figure 4. Baseline functional connectivity in the motor networks predicts long-term memory components. $A$, Learning rate during day 2 was predicted by baseline functional connectivity between cerebellum and thalamus (left), but not by the baseline connectivity between the thalamus and M1 (right). $\boldsymbol{B}$, The magnitude of relearning effect was predicted by baseline functional connectivity between the cerebellum and the thalamus (left), but not by the baseline connectivity between the thalamus and M1 (right). $C$, Magnitude of recall as estimated by the initial bias was predicted by baseline functional connectivity between the thalamus and M1 (left), but not by the baseline connectivity between the cerebellum and the thalamus (right). The value of $r$ represents the Pearson correlation coefficient.

baseline functional connectivity between the left leg area of the cerebellum and the right thalamus strongly predicts the magnitude of relearning effects ( $r=0.64, p=0.0058$; Fig. $4 B$, left). Subjects who showed high connectivity between cerebellum and thalamus at baseline also showed a greater relearning effect. Such correlation was not found when looking at the functional connectivity between thalamus and motor cortex $(r=-0.03, p=0.88$; Fig. $4 B$, right). Conversely, we found a significant correlation between baseline functional connectivity of the right thalamus and left M1 with the strength of memory recall as quantified by the initial bias $(r=0.58, p=0.015$; Fig. $4 C$, left $)$. This result suggests that individuals who have stronger baseline connectivity between thalamus and motor cortex were better at recall of previous actions from the mem- 
A

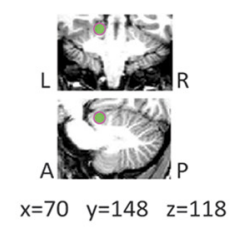

LL Cerbellum (Day1 U Day2)

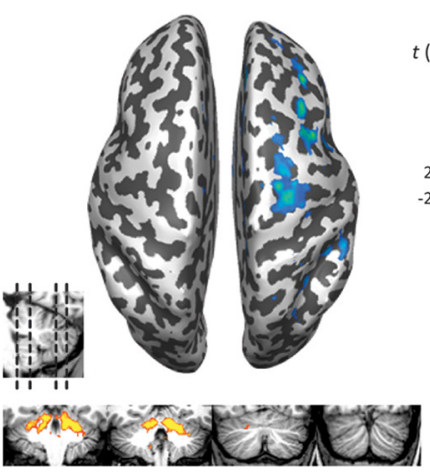

B

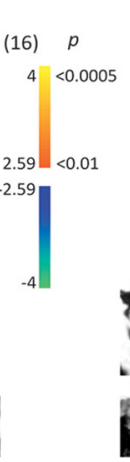

LL Cerbellum (Day2 > Day1)

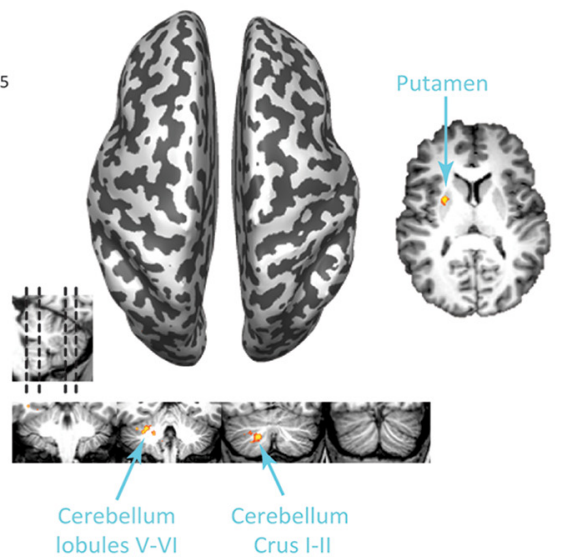

$\mathbf{F}$

C

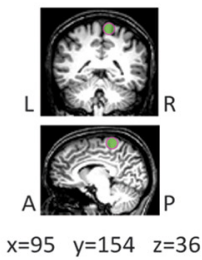

LL M1 (Day1 U Day2)
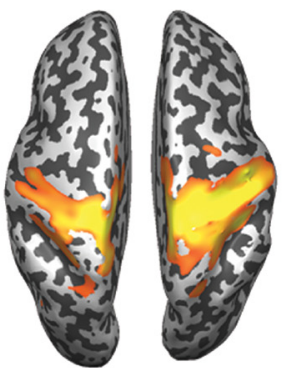

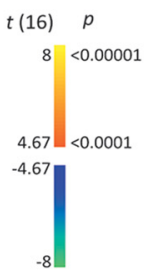

D

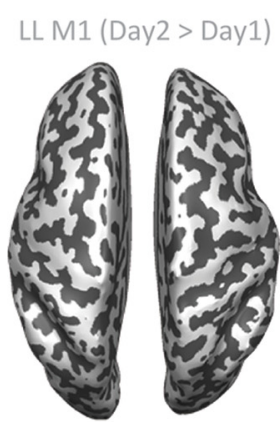

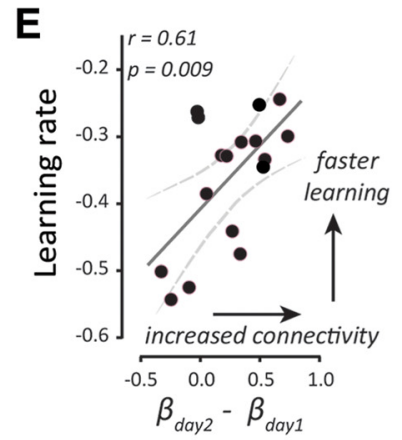

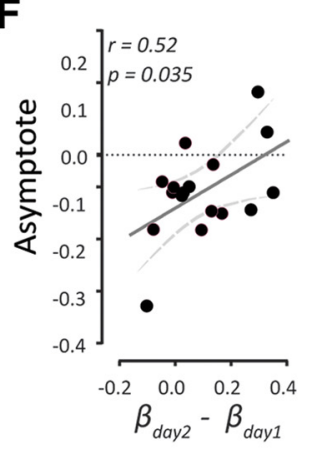

Figure 5. Modulation of cerebellar and M1 networks across the brain-seed based analysis. $A$, Left, Cerebellum seed region. Right, $z$-map of voxels that show significant correlation with the cerebellum ROI during the two scans (conjunction analysis: day $1 \cap$ day 2). B, $z$-map of voxels showing a significant correlation increase with the cerebellum after adaptation (contrast analysis: day $2>$ day 1). C, $\boldsymbol{D}$, Same as $\boldsymbol{A}$ and $\boldsymbol{B}$ but for M1. Results are shown after cluster-level correction for multiple comparisons $(p<0.05)$. $\boldsymbol{E}$, Changes in connectivity estimated by the GLM model (i.e., change in $\beta$ values) within the cerebellum were correlated with the learning rate in the first adaptation session. $\boldsymbol{F}$, Increased functional connectivity between the cerebellum and the putamen was positively correlated with asymptotic performance in the first adaptation session. The value of $r$ represents the Pearson correlation coefficient.

ory than individuals who showed weaker baseline connectivity. Functional connectivity between cerebellum and thalamus did not predict recall ( $r=0.23, p=0.37$; Fig. $4 C$, right).

These dissociable results suggest that across-subject variability in the retention of long-term motor memories can be partially explained by the ongoing interaction between nodes in the motor network. Baseline functional connectivity between cerebellum and M1, however, was not correlated with relearning effect nor with recall $(r<0.09, p>0.71)$. We suggest that the negative and positive correlations between the cerebellum-thalamus functional connectivity and the learning and relearning effects stem from a ceiling effect in the learning capacity in our subjects. Namely, individuals who already showed high learning rate in the first adaptation session are more likely to show smaller improvement when they are reexposed to the same perturbation on the second day. This interpretation suggests that learning and relearning rates are negatively correlated. Indeed, we find a negative correlation between these measures $(r=-0.628, p=0.0069)$. To verify that the correlation results that we found among baseline functional connectivity, relearning effect, and recall were not a result of the small sample that might be affected by outliers, we used a bootstrap test to estimate the effect of possible outliers on our results (see Materials and Methods). Bootstrap results refute the null hypothesis of zero correlation between cerebellarthalamic baseline functional connectivity and learning rate $(p=$ $0.0024)$, as well as correlation with relearning effect $(p=0.0009)$.
Furthermore, bootstrapped correlation between thalamiccortical baseline functional connectivity and recall showed a significant result ( $p=0.0014$ ). To further verify that our correlation results were not affected by outliers, we ran a robust regression analysis (see Materials and Methods) and found consistent correlations between the connectivity of all networks of interest and the behavioral measures.

\section{Connectivity changes within the cerebellum and between the} cerebellum and the basal ganglia

In the two preceding sections, we based our hypotheses on localized predictions and limited our analysis of connectivity to the motor cerebellar-thalamic-cortical networks to obviate multiplecomparisons concerns. Nevertheless, each one of our primary nodes is also connected anatomically and functionally to other brain areas. Which brain areas outside of the cerebellar-thalamiccortical network show changes in functional connectivity with that network after adaptation? To answer this question, we calculated seed-based functional connectivity maps. We examined the networks that are connected to the seeds of interest in the cerebellum (lobule IV of anterior lobe) and in the motor cortex. In the cerebellum, we detected positive correlations between the seed and lobules IV to VI of the anterior lobe and regions in the posterolateral cerebellum (crus I) and a negative correlation with areas in the cortex including premotor and primary motor areas (Fig. 5A). To determine whether we could find changes in the 
Table 1. Brain regions positively correlated with our cerebellar seed and significantly changed after adaptation

\begin{tabular}{|c|c|c|c|c|c|c|}
\hline \multirow[b]{2}{*}{ Region } & \multirow[b]{2}{*}{ Side } & \multicolumn{3}{|c|}{ Talairach coordinates } & \multirow{2}{*}{$\begin{array}{l}\text { Volume } \\
\left(\mathrm{mm}^{3}\right)\end{array}$} & \multirow{2}{*}{$\begin{array}{l}\text { Peak } \\
\text { z-value }\end{array}$} \\
\hline & & $x$ & $y$ & $z$ & & \\
\hline Cerebellum (lobules VI-V) & $\mathrm{L}$ & 22.6 & -41 & -25.4 & 466 & 4.175 \\
\hline Cerebellum (crus I-II) & $\mathrm{L}$ & 21.5 & -63.9 & -32.5 & 722 & 4.829 \\
\hline Putamen & $\mathrm{L}$ & 22.1 & 2.1 & 11.9 & 229 & 3.675 \\
\hline
\end{tabular}

Local cerebellar (i.e. Iobules VI-V and crus I-II) and cerebellar-basal ganglia (i.e. putamen) networks showed enhanced functional connectivity after adaptation (corresponds to Fig. 5B). Significance for all voxels was tested with a group mixed-effects analysis.

connectivity patterns after adaptation across the entire brain, we ran a contrast between the correlation patterns before and after training on a voxel-by-voxel basis. We found that, after adaptation, functional connectivity within the cerebellum increased significantly (Fig. 5B, Table 1). Interestingly, we detected a significant increase in functional connectivity between the cerebellum and the putamen (Fig. 5B, Table 1). Regression analysis revealed that the changes in connectivity (i.e., change in $\beta$ values) of these two regions are correlated with the performance of the subjects in the first adaptation session; the connectivity patterns within the cerebellum were correlated with the learning rate $(r=0.61, p=$ 0.009 ; Fig. 5E, Table 1 ) and connectivity changes with the putamen were positively correlated with asymptotic performance $(r=0.52, p=0.035$; Fig. 5F, Table 1$)$. M1-seed-based analysis revealed positive correlation with the primary and secondary sensorimotor areas (SMA, pre-SMA, and PMd) and area 5 of the posterior parietal cortex (Fig. $5 C$ ). The correlation patterns with M1, however, did not change after adaptation (Fig. $5 D$ ). To verify that the correlation results are not affected by outliers, we performed a bootstrap analysis (see Materials and Methods) on the correlation between the learning rate and the asymptotic performance and the connectivity changes measures. We found that bootstrapped correlation between changes in connectivity estimated by the GLM (i.e., change in $\beta$ values) within the cerebellum and the learning rate in the first adaptation session showed a pattern similar to our reported parametric result $(p=0.0104)$. We also found a significant bootstrapped correlation $(p=$ 0.0244 ) between changes in connectivity estimated by the GLM (i.e., change in $\beta$ values) between cerebellum-putamen and the asymptotic performance of the first adaptation session (corresponds to Fig. $5 F$ ).

\section{ICA}

We performed exploratory data-driven analysis by using ICA. This method allows the identification of major networks on a subject-by-subject basis during the resting-state scans and measuring changes in the strength of these components after motor adaptation. We focused our analysis on three previously reported resting-state networks of interest (Albert et al., 2009b): the sensorimotor, cerebellar, and frontoparietal networks (Fig. 6A). First, we compared the averaged component-related activation across the networks before and after learning. This analysis did not reveal any global change in the components $\left(t_{(16)} \leq 0.86, p \geq\right.$ 0.40 for all comparisons). We then examined the strength of these components on the voxel level using contrasts. Running this analysis on the sensorimotor component, we found increased component-related activity in a cluster within the lateral section of the central sulcus (primary motor cortex; see Fig. 6B, left). In the cerebellar component, we found increased componentrelated activation (Fig. $6 \mathrm{~B}$, middle) and, in the frontoparietal network, we found decrease component-related activation in the inferior parietal lobule of both hemispheres (Fig. $6 B$, right). The new results extended our previous seed-based findings by showing connectivity changes within the cortical and the cerebellar networks. The increased connectivity of the cerebellar network is consistent with our cerebellar-seed-based analysis and provides additional evidence of the critical role of the cerebellum in shortterm and long-term motor memory. We suggest that the reduction in component activation in the prefrontal circuit may be associated with a decrease in attentional and cognitive demands during the second exposure to the treadmill. This region is commonly activated during tasks that place demands on goal planning, working memory, and attentional filtering (Dosenbach et al., 2006; Power et al., 2011; Kelley et al., 2015).

\section{Discussion}

Integration of behavioral and resting-state functional connectivity measures allowed us to examine the neural processes that are involved in locomotor adaptation, recall, and relearning. First, we found that locomotor learning is associated with connectivity changes in the cerebellar-thalamic-cortical and cerebellar-basal ganglia networks and predicted by baseline cerebellar-thalamic resting connectivity. Locomotor adaption led to significant changes in behavior when subjects came to the laboratory after the adaptation session. These changes were seen through recall, which was associated with changes in the thalamic-cortical network, and the relearning effect, which was associated with changes in cerebellar-thalamic network.

\section{Connectivity modulation in the}

\section{cerebellar-thalamic-cortical network}

In support of our hypotheses, we found modulation of the connectivity in the cerebellar-thalamic-cortical network after the locomotor adaptation. The cerebellar-thalamic tract of the superior cerebellar peduncle connect the cerebellar hemisphere to the contralateral thalamus, which in turn projects to areas in the motor cortex (Sakai et al., 2002; Jeljeli et al., 2003; Stepniewska et al., 2003). Previous brain stimulation (Galea et al., 2011; Jayaram et al., 2012), neuroimaging (Albert et al., 2009b; Vahdat et al., 2011; Della-Maggiore et al., 2015a; Kim et al., 2015; Villalta et al., 2015), and lesions studies (Chen et al., 2006; Reisman et al., 2007; Tseng et al., 2007; Choi et al., 2009; Xu-Wilson et al., 2009) provide evidence for the critical involvement of the nodes of this network in motor learning. Consistent with our observation, Chen et al. (2006) found that disrupting the cerebellar-thalamic pathway either by deep brain stimulation or by thalamotomy largely impaired the ability to adapt to external perturbation. Although connectivity in the cerebellar-thalamic network increased, connectivity between the cerebellum and M1 decreased after adaptation. This result could be explained by the inhibitory circuit of the Purkinje cells that forms an inhibitory synapse with the deep cerebellar nuclei that send excitatory output to the motor cortex (Shehzad et al., 2009; Yan et al., 2009; Ma et al., 2010; Vahdat et al., 2011).

Although the thalamus went almost unnoticed in previous studies, we speculate that this site plays a role in the formation of long-term memories. The reported connectivity changes with the thalamus is consistent with a recent study that found that the activity of the thalamus and the cerebellum significantly increased after a visuomotor adaptation task, an activity that showed strong correlation with savings (i.e., increased relearning rate; Debas et al., 2010). Given the excitatory connections between the three ROIs and based on the increase in correlations between the thalamus and the cerebellum, one would expect to see an increase in connectivity with the motor cortex as well. The 
A

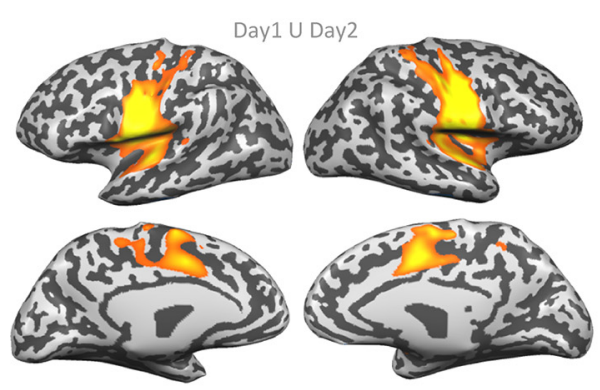

B

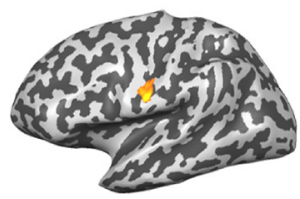

Day2 $>$ Day 1

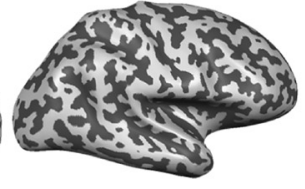

Cerebellar network

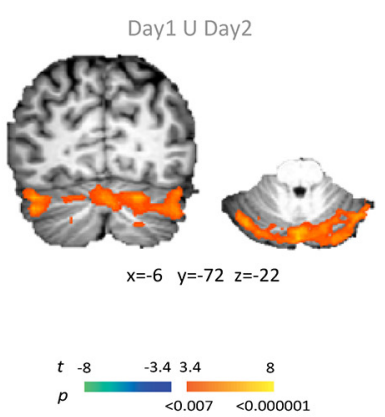

Day2 $>$ Day1

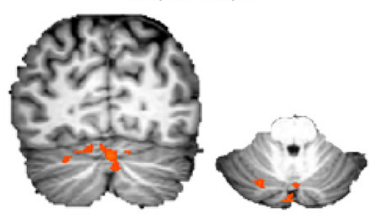

Fronto-Parietal network
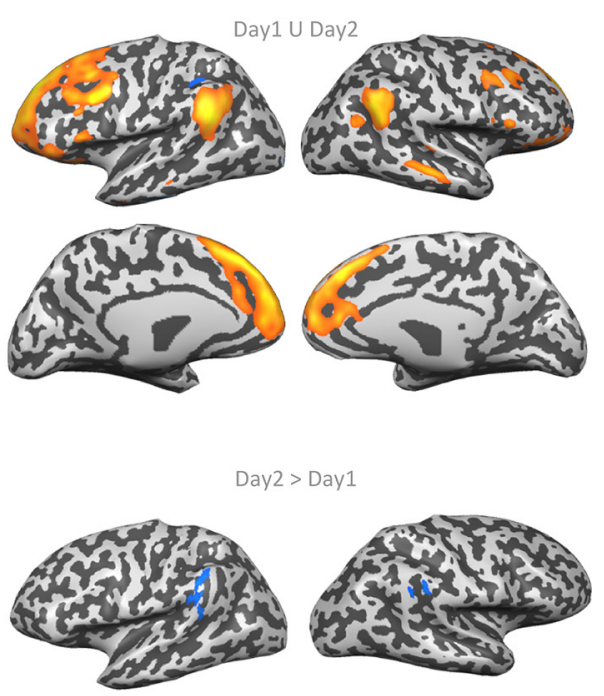

Figure 6. Three resting-state networks of interest identified by ICA. $A$, Left, ICA component corresponding to the sensorimotor network. Middle, ICA component corresponding to the cerebellar network. Right, ICA component corresponding to the frontoparietal network. Data show activation maps of networks of interest detected by the ICA algorithm. $B$, Contrasts of the three networks between day 1 (before learning) and day 2 (after learning). Left, Sensorimotor network. Middle, Cerebellar network. Right, Frontoparietal network. Color maps represent significant voxels of higher or lower component-related activity in day 2 compared with day 1.

fact that this result was not found suggests the existence of qualitative differences between the interactions between the reported ROI. One potential explanation is that the increased cerebellarthalamic connectivity is driven mainly by an intrinsic change in the cerebellum signal rather than increased in the synchronization between the two sites.

\section{Baseline connectivity reflects an idiosyncratic combination of adaptation processes}

Our intersubject correlation results suggest that functional connectivity at rest might reflect a fundamental trait that is indicative of the function of the network during adaptation and long-term memory formation. A growing body of research demonstrates the fundamental role of baseline network architecture in explaining individual differences in a variety of behaviors, such as motor sequence learning (Bonzano et al., 2015), intelligence quotient (Santarnecchi et al., 2015), performance in working memory tasks (Sala-Llonch et al., 2012; Zou et al., 2013), detection external sensory stimulus (Sadaghiani et al., 2015), and learning ability for foreign sounds (Ventura-Campos et al., 2013). There are two key factors that have been discussed previously and might explain partially some of the differences across individuals at baseline: prior experience (Albert et al., 2009b; Barnes et al., 2009; Gerraty et al., 2014) and brain structural connectivity (Hermundstad et al., 2013; Hermundstad et al., 2014; Shen et al., 2015). We suggest that anatomical connectivity analyses and estimation of multiple learning abilities in individual subjects may shed more light on this topic.

Recall and relearning effect are two distinct behavioral phenomena that are related to the retention of long-term motor memories. These two phenomena are likely to be the outcome of different learning mechanisms that operate during adaptation (Huang et al., 2011; Shmuelof et al., 2012; Taylor et al., 2014; Orban de Xivry and Lefèvre, 2015). We suggest that the variability in relearning effect and in recall across subjects reflects an idiosyncratic combination of learning processes that operates during the adaptation phase (Huang et al., 2011; Shmuelof et al., 2012).
Although both of these processes drive the adaptation, each one of them leads to a different memory component that can be probed by generalization, retention, and reexposure to the perturbation.

We argue that functional connectivity reflects the modularity of the network. Modules (ROIs in our case) that are heavily interconnected will tend to be more synchronized with one another and may therefore show decreased or limited ability to adapt separately to changes in the environment. Conversely, modules that are sparsely interconnected may have increased potential for adaptability (Mattar et al., 2016). From this perspective, the negative correlation between the learning rate and the functional connectivity between the cerebellum and the thalamus could be explained by the fact that individuals who showed reduced synchronization (i.e., reduced functional connectivity) between the two modules have increased ability to adapt to the changes in the environment compared with subjects that have increased synchronization (i.e., increased functional connectivity), which by itself decreases the ability to adapt. Support for this hypothesis comes from a recent study showing that that increased modularity (decreased functional connectivity) is positively correlated with improvement in attention and executive function after cognitive training (Arnemann et al., 2015). Although performing a new task might be affected by the modularity of the dynamic system, forming the memory may be affected by the integration and the strength of the network. This interpretation is consistent with the report by Wang et al. (2010) demonstrating that that connectivity within the DMN measured just before the execution of an associative memory task can predict interindividual differences in memory performance.

\section{Involvement of cerebellar-cerebellar and cerebellar-basal} ganglia networks during the adaptation process

Plasticity related to locomotor learning is not restricted to the cerebellar-thalamic-cortical network, but can also be seen within the cerebellum and between the cerebellum and the basal ganglia. Importantly, the modulation in these two networks was 
correlated with different components of the initial adaptation; local cerebellar networks were correlated with the learning rate, whereas cerebellar-basal ganglia circuit changes were correlated with the asymptotic phase of the adaptation. This result may support the idea that these two cerebellar-related networks are involved in two different adaptation processes. The connectivity change within the cerebellum after adaptation is consistent with a recent study showing a similar pattern of connectivity between crus I and lobule VIII of the ipsilateral cerebellum during visuomotor adaptation (Della-Maggiore et al., 2015b). The correlation between the connectivity change within the cerebellum and the early phase of the adaptation points to the dominant contribution of the cerebellum early in the learning process (Doyon et al., 2003; Penhune and Doyon, 2005; Bastian, 2006). These observations suggest that the cerebellum appears to play an important role, not only for online prediction-error correction (Martin et al., 1996; Smith and Shadmehr, 2005; Tseng et al., 2007), but also for consolidation of the memory associated with the adaptation (Vahdat et al., 2011; Sami et al., 2014; Della-Maggiore et al., 2015b).

Our results showing that the correlation between the cerebellum and the putamen of the basal ganglia increased after adaptation and that this change was related to the asymptotic performance provide novel evidence for the functional interconnection between the cerebellum and the basal ganglia. This link is important because it provides evidence for the involvement of the basal ganglia in adaptation learning, supporting the involvement of multiple learning processes in adaptation (Doya, 2000; Doyon et al., 2003; Penhune and Doyon, 2005; Doyon et al., 2009; Bostan et al., 2013). These findings can be interpreted as reflecting a reinforcement learning process through the process of repetition of successful actions on asymptote when the successful action converged upon by adaptation is repeated (Huang et al., 2011; Shmuelof et al., 2012). Therefore, we suggest that, during asymptotic performance, the optimal solution found by adaptation leads to an increase in rewarding signals that engage reinforcement mechanism (Shmuelof et al., 2012; Haith and Krakauer, 2013). Developing estimates of error-based and reinforcementbased learning during locomotor adaptation may allow addressing the proposed linkage among recall, relearning, and adaptation processes.

The fact that a short exposure to a task leads to large-scale connectivity changes that are observable by fMRI is thought provoking. It could be a reflection of a short-term increase in synaptic formation that may subsequently support the formation of new connections between neurons (Xu et al., 2009). In that case, the increase in connectivity is expected to be transient (Xu et al., 2009) and may be harnessed for other learning behaviors in the same network (Kilgard, 2012). Alternatively, these changes may reflect long-term changes in connectivity. In that case, the inconsistency between the large-scale connectivity changes (Della-Maggiore and McIntosh, 2005; Debas et al., 2010; Della-Maggiore et al., 2015b) and the narrow generalization that is typically reported in adaptation learning (Krakauer et al., 2000) may suggest that the connectivity changes are driven by a selective ensemble of neurons in each region.

The extent to which the change in connectivity relates to memory components of other tasks performed by other effectors remains to be determined. Although the recall and relearning effects were typically combined in previous resting-state connectivity studies, we speculate that comparable connectivity changes will be found in the hand network after reaching adaptation. This assertion is based on a similarity among the long-term memory components, recall and relearning effects, that are described in the two behaviors (Smith et al., 2006; Malone et al., 2011; Mawase et al., 2014; Huberdeau et al., 2015; Roemmich and Bastian, 2015; Mawase et al., 2016) and on recent reports showing that sensorimotor adaptation in reaching lead to modulation of functional connectivity in a local network within the cerebellum and in a network that includes the motor and premotor cortices, cerebellum, and putamen (Albert et al., 2009b; Debas et al., 2010; Vahdat et al., 2011; Vahdat et al., 2014). In addition, the fact that the strengthening of this network correlated positively with longterm retention in hand reaching under visuomotor adaptation (Della-Maggiore et al., 2015b) provides further support for this conjecture.

\section{References}

Albert NB, Robertson EM, Mehta P, Miall RC (2009a) Resting state networks and memory consolidation. Commun Integr Biol 2:530-532. CrossRef Medline

Albert NB, Robertson EM, Miall RC (2009b) The resting human brain and motor learning. Curr Biol 19:1023-1027. CrossRef Medline

Arnemann KL, Chen AJ, Novakovic-Agopian T, Gratton C, Nomura EM, D'Esposito M (2015) Functional brain network modularity predicts response to cognitive training after brain injury. Neurology 84:1568-1574. CrossRef Medline

Barnes A, Bullmore ET, Suckling J (2009) Endogenous human brain dynamics recover slowly following cognitive effort. PLoS One 4:e6626. CrossRef Medline

Bassett DS, Yang M, Wymbs NF, Grafton ST (2015) Learning-induced autonomy of sensorimotor systems. Nat Neurosci 18:744-751. CrossRef Medline

Bastian AJ (2006) Learning to predict the future: the cerebellum adapts feedforward movement control. Curr Opin Neurobiol 16:645-649. CrossRef Medline

Beckmann CF, DeLuca M, Devlin JT, Smith SM (2005) Investigations into resting-state connectivity using independent component analysis. Philos Trans R Soc Lond B Biol Sci 360:1001-1013. CrossRef Medline

Bonzano L, Palmaro E, Teodorescu R, Fleysher L, Inglese M, Bove M (2015) Functional connectivity in the resting-state motor networks influences the kinematic processes during motor sequence learning. Eur J Neurosci 41:243-253. CrossRef Medline

Bostan AC, Dum RP, Strick PL (2013) Cerebellar networks with the cerebral cortex and basal ganglia. Trends Cogn Sci 17:241-254. CrossRef Medline

Censor N, Horovitz SG, Cohen LG (2014) Interference with existing memories alters offline intrinsic functional brain connectivity. Neuron 81 : 69-76. CrossRef Medline

Chambers W, Sprague JM (1955) Functional localization in the cerebellum. I. Organization in longitudinal cortico-nuclear zones and their contribution to the control of posture, both extrapyramidal and pyramidal. J Comp Neurol 103:105-129. CrossRef Medline

Chen H, Hua SE, Smith MA, Lenz FA, Shadmehr R (2006) Effects of human cerebellar thalamus disruption on adaptive control of reaching. Cereb Cortex 16:1462-1473. Medline

Choi JT, Vining EP, Reisman DS, Bastian AJ (2009) Walking flexibility after hemispherectomy: split-belt treadmill adaptation and feedback control. Brain 132:722-733. CrossRef Medline

Coffman KA, Dum RP, Strick PL (2011) Cerebellar vermis is a target of projections from the motor areas in the cerebral cortex. Proc Natl Acad Sci U S A 108:16068-16073. CrossRef Medline

Cole MW, Bassett DS, Power JD, Braver TS, Petersen SE (2014) Intrinsic and task-evoked network architectures of the human brain. Neuron 83: 238-251. CrossRef Medline

Debas K, Carrier J, Orban P, Barakat M, Lungu O, Vandewalle G, Hadj Tahar A, Bellec P, Karni A, Ungerleider LG, Benali H, Doyon J (2010) Brain plasticity related to the consolidation of motor sequence learning and motor adaptation. Proc Natl Acad Sci U S A 107:17839-17844. CrossRef Medline

Della-Maggiore V, McIntosh AR (2005) Time course of changes in brain activity and functional connectivity associated with long-term adaptation to a rotational transformation. J Neurophysiol 93:2254-2262. Medline

Della-Maggiore V, Landi SM, Villalta JI (2015a) Sensorimotor adaptation 
multiple forms of plasticity in motor circuits. Neuroscientist 21:109-125. CrossRef Medline

Della-Maggiore V, Villalta JI, Kovacevic N, McIntosh AR (2015b) Functional evidence for memory stabilization in sensorimotor adaptation: a 24-h resting-state fMRI study. Cereb Cortex. Advance online publication December 8, 2015. doi: 10.1093/cercor/bhv289.

Dosenbach NU, Visscher KM, Palmer ED, Miezin FM, Wenger KK, Kang HC, Burgund ED, Grimes AL, Schlaggar BL, Petersen SE (2006) A core system for the implementation of task sets. Neuron 50:799-812. CrossRef Medline

Doya K (2000) Complementary roles of basal ganglia and cerebellum in learning and motor control. Curr Opin Neurobiol 10:732-739. CrossRef Medline

Doyon J, Penhune V, Ungerleider LG (2003) Distinct contribution of the cortico-striatal and cortico-cerebellar systems to motor skill learning. Neuropsychologia 41:252-262. CrossRef Medline

Doyon J, Bellec P, Amsel R, Penhune V, Monchi O, Carrier J, Lehéricy S, Benali H (2009) Contributions of the basal ganglia and functionally related brain structures to motor learning. Behav Brain Res 199:61-75. CrossRef Medline

Ebbinghaus H (1913) Memory: a contribution to experimental psychology. New York: Dover.

Fabre M, Andre C, Buser P (1979) Testing visually guided forepaw movements in the cat: training apparatus and procedure. Physiol Behav 23: 263-266. CrossRef Medline

Fox MD, Raichle ME (2007) Spontaneous fluctuations in brain activity observed with functional magnetic resonance imaging. Nat Rev Neurosci 8:700-711. CrossRef Medline

Galea JM, Vazquez A, Pasricha N, de Xivry JJ, Celnik P (2011) Dissociating the roles of the cerebellum and motor cortex during adaptive learning: the motor cortex retains what the cerebellum learns. Cereb Cortex 21:17611770. CrossRef Medline

Gerraty RT, Davidow JY, Wimmer GE, Kahn I, Shohamy D (2014) Transfer of learning relates to intrinsic connectivity between hippocampus, ventromedial prefrontal cortex, and large-scale networks. J Neurosci 34: 11297-11303. CrossRef Medline

Ghez C, Thach W (2000) The cerebellum. In: Principles of neuroscience (Kandel ER, Schwartz JH, Jessell TM, eds), pp 832-852. New York: McGraw-Hill.

Hahamy A, Sotiropoulos SN, Slater DH, Malach R, Johansen-Berg H, Makin TR (2015) Normalisation of brain connectivity through compensatory behaviour, despite congenital hand absence. Elife 4. CrossRef Medline

Haith AM, Krakauer JW (2013) Model-based and model-free mechanisms of human motor learning. In: Progress in motor control. (Richardson MJ, Riley MA, Shockley K, eds), pp 1-21. New York: Springer.

Hermundstad AM, Bassett DS, Brown KS, Aminoff EM, Clewett D, Freeman S, Frithsen A, Johnson A, Tipper CM, Miller MB, Grafton ST, Carlson JM (2013) Structural foundations of resting-state and task-based functional connectivity in the human brain. Proc Natl Acad Sci U S A 110:61696174. CrossRef Medline

Hermundstad AM, Brown KS, Bassett DS, Aminoff EM, Frithsen A, Johnson A, Tipper CM, Miller MB, Grafton ST, Carlson JM (2014) Structurallyconstrained relationships between cognitive states in the human brain. PLoS Comput Biol 10:e1003591. CrossRef Medline

Herzfeld DJ, Vaswani PA, Marko MK, Shadmehr R (2014) A memory of errors in sensorimotor learning. Science 345:1349-1353. CrossRef Medline

Horak FB, Diener HC (1994) Cerebellar control of postural scaling and central set in stance. J Neurophysiol 72:479-493. Medline

Huang VS, Haith A, Mazzoni P, Krakauer JW (2011) Rethinking motor learning and savings in adaptation paradigms: model-free memory for successful actions combines with internal models. Neuron 70:787-801. CrossRef Medline

Huberdeau DM, Haith AM, Krakauer JW (2015) Formation of a long-term memory for visuomotor adaptation following only a few trials of practice. J Neurophysiol 114:969-977. CrossRef Medline

Ilg W, Giese MA, Gizewski ER, Schoch B, Timmann D (2008) The influence of focal cerebellar lesions on the control and adaptation of gait. Brain 131:2913-2927. CrossRef Medline

Jayaram G, Galea JM, Bastian AJ, Celnik P (2011) Human locomotor adaptive learning is proportional to depression of cerebellar excitability. Cereb Cortex 21:1901-1909. CrossRef Medline
Jayaram G, Tang B, Pallegadda R, Vasudevan EV, Celnik P, Bastian A (2012) Modulating locomotor adaptation with cerebellar stimulation. J Neurophysiol 107:2950-2957. CrossRef Medline

Jeljeli M, Strazielle C, Caston J, Lalonde R (2003) Effects of ventrolateralventromedial thalamic lesions on motor coordination and spatial orientation in rats. Neurosci Res 47:309-316. CrossRef Medline

Kelley WM, Wagner DD, Heatherton TF (2015) In search of a human selfregulation system. Annu Rev Neurosci 38:389-411. CrossRef Medline

Kilgard MP (2012) Harnessing plasticity to understand learning and treat disease. Trends Neurosci 35:715-722. CrossRef Medline

Kim S, Ogawa K, Lv J, Schweighofer N, Imamizu H (2015) Neural substrates related to motor memory with multiple timescales in sensorimotor adaptation. PLoS Biol 13:e1002312. CrossRef Medline

Krakauer JW, Pine ZM, Ghilardi MF, Ghez C (2000) Learning of visuomotor transformations for vectorial planning of reaching trajectories. J Neurosci 20:8916-8924. Medline

Krakauer JW, Ghez C, Ghilardi MF (2005) Adaptation to visuomotor transformations: consolidation, interference, and forgetting. J Neurosci 25: 473-478. CrossRef Medline

Landi SM, Baguear F, Della-Maggiore V (2011) One week of motor adaptation induces structural changes in primary motor cortex that predict long-term memory one year later. J Neurosci 31:11808-11813. CrossRef Medline

Ma L, Wang B, Narayana S, Hazeltine E, Chen X, Robin DA, Fox PT, Xiong J (2010) Changes in regional activity are accompanied with changes in inter-regional connectivity during 4 weeks motor learning. Brain Res 1318:64-76. CrossRef Medline

Makin TR, Scholz J, Filippini N, Henderson Slater D, Tracey I, Johansen-Berg $\mathrm{H}$ (2013) Phantom pain is associated with preserved structure and function in the former hand area. Nat Commun 4:1570. CrossRef Medline

Malone LA, Vasudevan EV, Bastian AJ (2011) Motor adaptation training for faster relearning. J Neurosci 31:15136-15143. CrossRef Medline

Martin TA, Keating JG, Goodkin HP, Bastian AJ, Thach WT (1996) Throwing while looking through prisms. Brain 119:1183-1198. CrossRef Medline

Mattar M, Wymbs NF, Bock AS, Aguirre GK, Grafton ST, Bassett DS (2016) Predicting future learning from baseline network architecture. bioRxiv. Advance online publication June 3, 2016. doi: 10.1101/05686.

Mawase F, Shmuelof L, Bar-Haim S, Karniel A (2014) Savings in locomotor adaptation explained by changes in learning parameters following initial adaptation. J Neurophysiol 111:1444-1454. CrossRef Medline

Mawase F, Bar-Haim S, Joubran K, Rubin L, Karniel A, Shmuelof L (2016) Increased adaptation rates and reduction in trial-by-trial variability in subjects with cerebral palsy following a multi-session locomotor adaptation training. Front Hum Neurosci 10:203. CrossRef Medline

McGregor HR, Gribble PL (2015) Changes in visual and sensory-motor resting-state functional connectivity support motor learning by observing. J Neurophysiol 114:677-688. CrossRef Medline

Middleton FA, Strick PL (1994) Anatomical evidence for cerebellar and basal ganglia involvement in higher cognitive function. Science 266:458 461. CrossRef Medline

Middleton FA, Strick PL (1997) Cerebellar output channels. Int Rev Neurobiol 41:61-82. CrossRef Medline

Morton SM, Bastian AJ (2006) Cerebellar contributions to locomotor adaptations during splitbelt treadmill walking. J Neurosci 26:9107-9116. CrossRef Medline

Orban de Xivry JJ, Lefèvre P (2015) Formation of model-free motor memories during motor adaptation depends on perturbation schedule. J Neurophysiol 113:2733-2741. CrossRef Medline

Penhune VB, Doyon J (2005) Cerebellum and M1 interaction during early learning of timed motor sequences. Neuroimage 26:801-812. CrossRef Medline

Power JD, Cohen AL, Nelson SM, Wig GS, Barnes KA, Church JA, Vogel AC, Laumann TO, Miezin FM, Schlaggar BL, Petersen SE (2011) Functional network organization of the human brain. Neuron 72:665-678. CrossRef Medline

Reisman DS, Block HJ, Bastian AJ (2005) Interlimb coordination during locomotion: what can be adapted and stored? J Neurophysiol 94:24032415. CrossRef Medline

Reisman DS, Wityk R, Silver K, Bastian AJ (2007) Locomotor adaptation on a split-belt treadmill can improve walking symmetry post-stroke. Brain 130:1861-1872. CrossRef Medline 
Reisman DS, Wityk R, Silver K, Bastian AJ (2009) Split-belt treadmill adaptation transfers to overground walking in persons poststroke. Neurorehabil Neural Repair 23:735-744. CrossRef Medline

Reuter M, Schmansky NJ, Rosas HD, Fischl B (2012) Within-subject template estimation for unbiased longitudinal image analysis. Neuroimage 61:1402-1418. CrossRef Medline

Roemmich RT, Bastian AJ (2015) Two ways to save a newly learned motor pattern. J Neurophysiol 113:3519-3530. CrossRef Medline

Sadaghiani S, Poline JB, Kleinschmidt A, D’Esposito M (2015) Ongoing dynamics in large-scale functional connectivity predict perception. Proc Natl Acad Sci U S A 112:8463-8468. CrossRef Medline

Sakai ST, Inase M, Tanji J (2002) The relationship between MI and SMA afferents and cerebellar and pallidal efferents in the macaque monkey. Somatosens Mot Res 19:139-148. CrossRef Medline

Sala-Llonch R, Peña-Gómez C, Arenaza-Urquijo EM, Vidal-Piñeiro D, Bargalló N, Junqué C, Bartrés-Faz D (2012) Brain connectivity during resting state and subsequent working memory task predicts behavioural performance. Cortex 48:1187-1196. CrossRef Medline

Sami S, Robertson EM, Miall RC (2014) The time course of task-specific memory consolidation effects in resting state networks. J Neurosci 34: 3982-3992. CrossRef Medline

Sampaio-Baptista C, Filippini N, Stagg CJ, Near J, Scholz J, Johansen-Berg H (2015) Changes in functional connectivity and GABA levels with longterm motor learning. Neuroimage 106:15-20. CrossRef Medline

Santarnecchi E, Tatti E, Rossi S, Serino V, Rossi A (2015) Intelligencerelated differences in the asymmetry of spontaneous cerebral activity. Hum Brain Mapp 36:3586-3602. CrossRef Medline

Shadmehr R, Brashers-Krug T (1997) Functional stages in the formation of human long-term motor memory. J Neurosci 17:409-419. Medline

Shadmehr R, Mussa-Ivaldi FA (1994) Adaptive representation of dynamics during learning of a motor task. J Neurosci 14:3208-3224. Medline

Shehzad Z, Kelly AC, Reiss PT, Gee DG, Gotimer K, Uddin LQ, Lee SH, Margulies DS, Roy AK, Biswal BB, Petkova E, Castellanos FX, Milham MP (2009) The resting brain: unconstrained yet reliable. Cereb Cortex 19: 2209-2229. CrossRef Medline

Shen K, Hutchison RM, Bezgin G, Everling S, McIntosh AR (2015) Network structure shapes spontaneous functional connectivity dynamics. J Neurosci 35:5579-5588. CrossRef Medline

Shmuelof L, Huang VS, Haith AM, Delnicki RJ, Mazzoni P, Krakauer JW (2012) Overcoming motor "forgetting" through reinforcement of learned actions. J Neurosci 32:14617-14621. CrossRef Medline

Smith MA, Shadmehr R (2005) Intact ability to learn internal models of arm dynamics in Huntington's disease but not cerebellar degeneration. J Neurophysiol 93:2809-2821. CrossRef Medline

Smith MA, Ghazizadeh A, Shadmehr R (2006) Interacting adaptive processes with different timescales underlie short-term motor learning. PLoS Biol 4:e179. CrossRef Medline

Stagg CJ, Bachtiar V, Amadi U, Gudberg CA, Ilie AS, Sampaio-Baptista C, O'Shea J, Woolrich M, Smith SM, Filippini N, Near J, Johansen-Berg H (2014) Local GABA concentration is related to network-level resting functional connectivity. Elife 3:e01465. CrossRef Medline

Stepniewska I, Sakai ST, Qi HX, Kaas JH (2003) Somatosensory input to the ventrolateral thalamic region in the macaque monkey: a potential substrate for parkinsonian tremor. J Comp Neurol 455:378-395. CrossRef Medline

Tambini A, Ketz N, Davachi L (2010) Enhanced brain correlations during rest are related to memory for recent experiences. Neuron 65:280-290. CrossRef Medline
Taubert M, Lohmann G, Margulies DS, Villringer A, Ragert P (2011) Longterm effects of motor training on resting-state networks and underlying brain structure. Neuroimage 57:1492-1498. CrossRef Medline

Taylor JA, Krakauer JW, Ivry RB (2014) Explicit and implicit contributions to learning in a sensorimotor adaptation task. J Neurosci 34:3023-3032. CrossRef Medline

Thoroughman KA, Shadmehr R (1999) Electromyographic correlates of learning an internal model of reaching movements. J Neurosci 19:85738588. Medline

Torres-Oviedo G, Bastian AJ (2012) Natural error patterns enable transfer of motor learning to novel contexts. J Neurophysiol 107:346-356. CrossRef Medline

Torres-Oviedo G, Vasudevan E, Malone L, Bastian AJ (2011) Locomotor adaptation. Prog Brain Res 191:65-74. CrossRef Medline

Tseng YW, Diedrichsen J, Krakauer JW, Shadmehr R, Bastian AJ (2007) Sensory prediction errors drive cerebellum-dependent adaptation of reaching. J Neurophysiol 98:54-62. CrossRef Medline

Vahdat S, Darainy M, Milner TE, Ostry DJ (2011) Functionally specific changes in resting-state sensorimotor networks after motor learning. J Neurosci 31:16907-16915. CrossRef Medline

Vahdat S, Darainy M, Ostry DJ (2014) Structure of plasticity in human sensory and motor networks due to perceptual learning. J Neurosci 34:24512463. CrossRef Medline

Ventura-Campos N, Sanjuán A, González J, Palomar-García MÁ, RodríguezPujadas A, Sebastián-Gallés N, Deco G, Ávila C (2013) Spontaneous brain activity predicts learning ability of foreign sounds. J Neurosci 33: 9295-9305. CrossRef Medline

Villalta JI, Landi SM, Fló A, Della-Maggiore V (2015) Extinction interferes with the retrieval of visuomotor memories through a mechanism involving the sensorimotor cortex. Cereb Cortex 25:1535-1543. CrossRef Medline

Wang L, Laviolette P, O’Keefe K, Putcha D, Bakkour A, Van Dijk KR, Pihlajamäki M, Dickerson BC, Sperling RA (2010) Intrinsic connectivity between the hippocampus and posteromedial cortex predicts memory performance in cognitively intact older individuals. Neuroimage 51:910917. CrossRef Medline

Wolpert DM, Kawato M (1998) Multiple paired forward and inverse models for motor control. Neural Netw 11:1317-1329. CrossRef Medline

Wymbs NF, Bassett DS, Mucha PJ, Porter MA, Grafton ST (2012) Differential recruitment of the sensorimotor putamen and frontoparietal cortex during motor chunking in humans. Neuron 74:936-946. CrossRef Medline

Xu T, Yu X, Perlik AJ, Tobin WF, Zweig JA, Tennant K, Jones T, Zuo Y (2009) Rapid formation and selective stabilization of synapses for enduring motor memories. Nature 462:915-919. CrossRef Medline

Xu-Wilson M, Chen-Harris H, Zee DS, Shadmehr R (2009) Cerebellar contributions to adaptive control of saccades in humans. J Neurosci 29: 12930-12939. CrossRef Medline

Yan H, Zuo XN, Wang D, Wang J, Zhu C, Milham MP, Zhang D, Zang Y (2009) Hemispheric asymmetry in cognitive division of anterior cingulate cortex: a resting-state functional connectivity study. Neuroimage 47: 1579-1589. CrossRef Medline

Zou Q, Ross TJ, Gu H, Geng X, Zuo XN, Hong LE, Gao JH, Stein EA, Zang YF, Yang Y (2013) Intrinsic resting-state activity predicts working memory brain activation and behavioral performance. Hum Brain Mapp 34:32043215. CrossRef Medline 